\title{
Liquid sodium-The heat transport medium in fast breeder reactors
}

\author{
C K MATHEWS \\ Chemical Group, Indira Gandhi Centre for Atomic Research, Kalpakkam 603 102, India
}

\begin{abstract}
Liquid sodium is used as a coolant in fast breeder reactors on account of its excellent heat transfer properties. It must, however, be in the pure form to be compatible with structural materials. Techniques for its purification to nuclear grade and its characterization had to be developed in our laboratory before we could embark on an R\&D programme.

It is essential to monitor hydrogen at ppb levels in the sodium circuits of the fast reactor in order to detect water leaks in the steam generator in a timely manner. Similarly it is useful to make on-line measurements of oxygen and carbon at trace levels. Electrochemical sensors have been developed in our laboratory for this purpose. These compact sensors work on the principle of concentration cells and are far superior to devices used elsewhere for this purpose.

Corrosion of structural materials in the sodium environment depends on the oxygen content of sodium. In order to understand the mechanism of this corrosion, one must have a good grasp of the thermochemistry of the ternary systems, $\mathrm{Na}-\mathrm{M}-\mathrm{O}$, where $\mathrm{M}$ stands for the alloying constituents of stainless steels. The phase diagrams of most of these systems were established in our laboratory. A specially designed sodium loop is used in the study of corrosion, activity transport and kinetics of sodium-water reaction.
\end{abstract}

Keywords. Sodium; nuclear reactors; nuclear materials; sensors; corrosion; ternary systems.

\section{Introduction}

Liquid sodium is an excellent heat transfer medium on account of its high thermal conductivity, high specific heat, low viscosity, long liquid range, remarkable thermal stability and good compatibility with structural materials. While water has been the ubiquitous heat transport fluid in power plants, it has many disadvantages when heat has to be extracted at high temperatures $\left(\sim 600^{\circ} \mathrm{C}\right)$ in order to improve the thermodynamic efficiency of energy conversion. On the other hand, sodium remains a liquid up to $883^{\circ} \mathrm{C}$. It is thus the preferred coolant in fast breeder reactors in which water cannot be used as a coolant on account of its unfavourable nuclear proportions. It is also used in heat pipes operating in the temperature range of $500-1000^{\circ} \mathrm{C}$ (Borgstedt and Mathews 1987).

\section{Fast breeder reactors}

Fast breeder reactors are being developed with the idea of producing electricity through fission energy while conserving our uranium resources. Natural uranium contains only $0.72 \%$ of the fissionable isotope ${ }^{235} \mathrm{U}$, which is what undergoes fission in thermal neutron reactors. However, in fast breeder reactors the more abundant $(99.28 \%)$ isotope, ${ }^{238} \mathrm{U}$, is converted to the fissile isotope of plutonium, ${ }^{239} \mathrm{Pu}$, at a rate which is faster than the rate of consumption of this fissile nuclide, and hence these reactors are called breeder reactors. Thus fast reactors breed or produce more fuel than they consume. 
The use of fast neutrons with their lower cross-section for fission demands high fissile (plutonium) concentration in the fuel. In order to minimize fuel inventory and to keep the breeding gain high, the core is kept very compact. This demands fuels which can generate and transfer power at high density and a very efficient heat transfer fluid (coolant). Sodium is the preferred coolant in fast reactors and the fuel may be a mixed oxide or mixed carbide of uranium and plutonium.

Liquid sodium, which is used as the coolant in the fast breeder reactor, is quite compatible, in the pure state, with the stainless steel structural materials. However, traces of impurities play an important role in corrosion, mass transport and other processes taking place in the heat transport loops of the reactor. Even parts per million (ppm) levels of oxygen cause corrosion in the high temperature sections of the loop and the corrosion products get transported through the liquid sodium medium to cooler parts. Some of these corrosion products and fission products which find their way into sodium can cause high radiation levels when they deposit on parts like heat exchangers and pumps, which have to be periodically maintained. Thus one must not only control and monitor the oxygen impurity level, but also understand the transport and deposition of radionuclides in the reactor. Carbon in sodium causes carburization or decarburization of structural steels depending on the 'temperature and concentration. What is really important is the thermodynamic activity of carbon in sodium, but it is not yet well established as to what chemical forms carbon takes in sodium and what their inter-relationships and transformation kinetics are.

When there is a leak in the steam generator of a fast reactor, water (or steam) leaks into sodium. Such leaks must be quickly identified so that remedial action can be taken before they worsen. One of the first indications of such a leak is the (dissolved) hydrogen (rather, the hydride) level in liquid sodium. Thus monitoring hydrogen levels in sodium with high sensitivity is an important task.

\section{Purification and characterization}

Sodium arrives at the reactor site in the form of the commercial product. Commercial sodium contains impurities at tens or huindreds of ppm or even more in some cases. The major impurities are oxygen and hydrogen arising from exposure to atmosphere, carbon, magnesium, calcium and chloride originating from the manufacturing process where graphite electrodes are used in the electrolysis of fused sodium chloride containing calcium chloride, and trace metals. This sodium is purified to reactor grade before it is charged into the reactor system. Quality control analysis is required at every stage of these operations. Once the sodium is in the reactor loop its purity level is monitored.

Extensive facilities have been set up in our Centre for the purification and characterization of nuclear grade sodium. For example, measurement of impurities like oxygen and hydrogen at ppm levels is a challenging task on account of the high chemical reactivity of sodium. However, chemical characterization of high purity sodium has become a routine task in our laboratory (Mathews 1982). Therefore, greater emphasis is given in this paper on the more recent developments of on-line measurements. 


\section{Steam generator leak detection}

In the steam generator, liquid sodium at a few bars pressure is separated from water or steam at a pressure of more than 150 bars by the walls of the steam generator tubes. In the event of a leak developing in these tubes, water (or steam) at high pressure gets injected into sodium, leading to the formation of sodium hydride (and sodium oxide) or sodium hydroxide depending upon the prevailing temperature. Sensors are required to detect this steam ingress into liquid sodium at the very inception of the leak, so that corrective action can be taken before the leak develops further.

The electrochemical hydrogen sensor developed in our laboratory consists of a hydrogen concentration cell wherein two electrode compartments are separated by a hydride-ion conducting solid electrolyte. Sodium containing dissolved hydrogen constitutes one electrode of the concentration cell while the other (reference) electrode establishes a well-defined hydrogen partial pressure. The cell can be represented as

$$
\mathrm{pH}_{2} \text { (sample) } / \mathrm{CaCl}_{2}-\mathrm{CaH}_{2} / \mathrm{pH}_{2} \text { (reference), }
$$

where $\mathrm{pH}_{2}$ represents the hydrogen partial pressure.

Solid $\mathrm{CaCl}_{2}$ containing $5-7.5 \mathrm{~mol}^{\circ} \% \mathrm{CaH}_{2}$ was chosen as the electrolyte, based on the observation of Smith (1974) that it conducts by hydride ions. The $\mathrm{CaCl}_{2}-\mathrm{CaH}_{2}$ electrolyte must be contained in a thin-walled iron membrane. $\mathrm{Li} / \mathrm{LiH}$ mixture is chosen as the reference electrode as it has the right hydrogen potential. This is also contained in a thin-walled iron cup which dips into the electrolyte (figure 1). The outer membrane, containing the electrolyte, is immersed in liquid sodium which is the sample electrode. Thus the inner membrane attains the equilibrium hydrogen potential of the reference electrode and the outer membrane that of liquid sodium

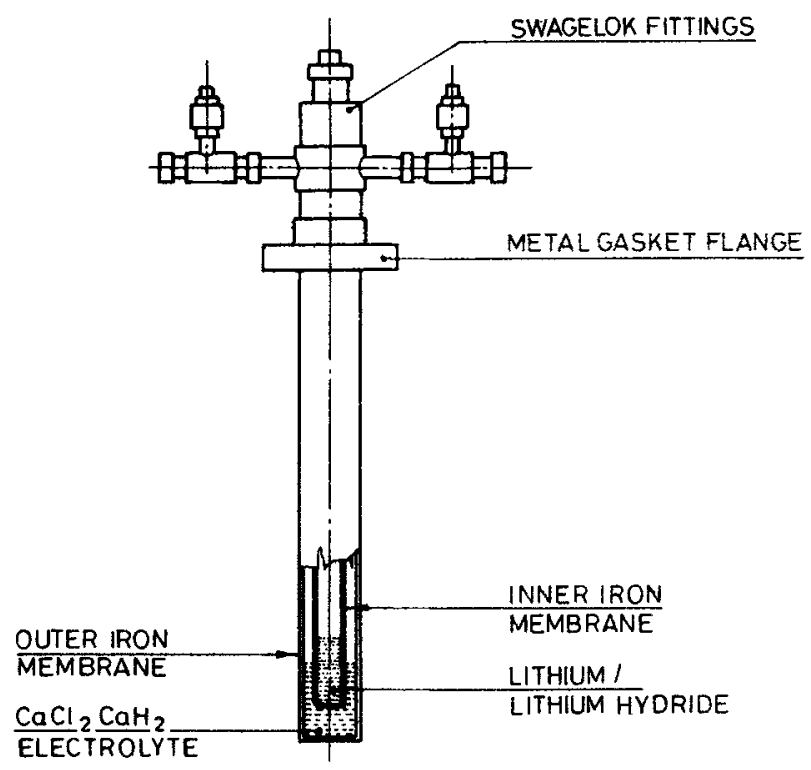

Figure 1. Electrochemical hydrogen sensor. Liquid sodium is not shown in the figure. 
at the temperature of operation. The electromotive force (EMF) of such a cell can be given as

$$
E=(R T / n F) \ln \left[\mathrm{pH}_{2}(\mathrm{ref}) / \mathrm{pH}_{2} \text { (sample) }\right],
$$

where $E$ is the EMF (V), $R$ the gas constant, $F$ the Faraday constant, $n=2$, and $T$ is the temperature $(\mathrm{K})$.

Hydrogen concentration in sodium, $[\mathrm{H}]_{\mathrm{Na}}$, is related to the equilibrium hydrogen pressure, $\left[\mathrm{pH}_{2}\right]$, by Sievert's law

$$
[\mathrm{H}]_{\mathrm{Na}}=K\left[\mathrm{pH}_{2}\right]^{1 / 2} \text {, }
$$

where $K$ is the Sievert's constant $\left[\mathrm{ppm} . \mathrm{Pa}^{-1 / 2}\right]$ when $\mathrm{pH}_{2}$ is in pascals $(\mathrm{Pa})$ and $[\mathrm{H}]_{\mathrm{Na}}$ is in ppm. Thus the hydrogen concentration in sodium can be obtained from the measured EMF

$$
E=(R T / 2 F)\left[\ln \mathrm{pH}_{2}(\mathrm{ref})-2 \ln [\mathrm{H}]_{\mathrm{Na}_{\mathrm{a}}}+2 \ln K\right] .
$$

A schematic of the electrochemical hydrogen sensor is shown in figure 1. The EMF is measured using a high impedance millivolt meter. These hydrogen sensors were tested in small laboratory scale sodium loops to evaluate their performance.

Each sensor was tested in such loops for long periods. The sensor temperature was usually fixed at $723 \mathrm{~K}$ and the cold trap temperature (which fixes the hydrogen level) was varied from 388 to $523 \mathrm{~K}$ simulating the range of hydrogen concentrations likely to be encountered in the reactor. The lowest hydrogen level achieved was dictated by the characteristics of the loop.

The hydrogen levels in sodium employed to test the sensors ranged from $47.5 \mathrm{ppb}$ to $1.7 \mathrm{ppm}$. These values were deduced from the cold trap temperatures in the loop by using the solubility data for hydrogen in sodium as reported by Funada et al (1979). The sensor can detect a change of $2 \mathrm{ppb}$ in the hydrogen level of sodium under operating conditions. This sensitivity level is adequate for use in the sodium circuits of a liquid metal cooled fast breeder reactor. These electrochemical hydrogen sensors have been incorporated into the secondary loops of FBTR, where their performance has been found to be very good. The new meters are simpler, more reliable and much less expensive than the diffusion type meter and, above all, are totally indigenous (Gnanasekaran et al 1990).

\section{Carbon in sodium}

Since carbon can exist in liquid sodium in both dissolved and undissolved forms, the total carbon content does not represent the carburizing potential of sodium. Since the driving force for carburization is the chemical potential, it is important to measure the carbon potential of sodium. On-line measurement is preferred as the process of sampling itself can alter the carbon chemistry in sodium. Prior to the present work, the only device that was developed to a level of testing in reactor circuits was the Harwell carbon meter (HCM) (Asher et al 1977) which was based on the diffusion of carbon through an iron membrane to form $\mathrm{CO}$ at the oxidized surface and its detection by gas chromatography after catalytic conversion to methane. This has been found to be unsatisfactory for reactor use on account of its complexity as well as the need for frequent calibration. 


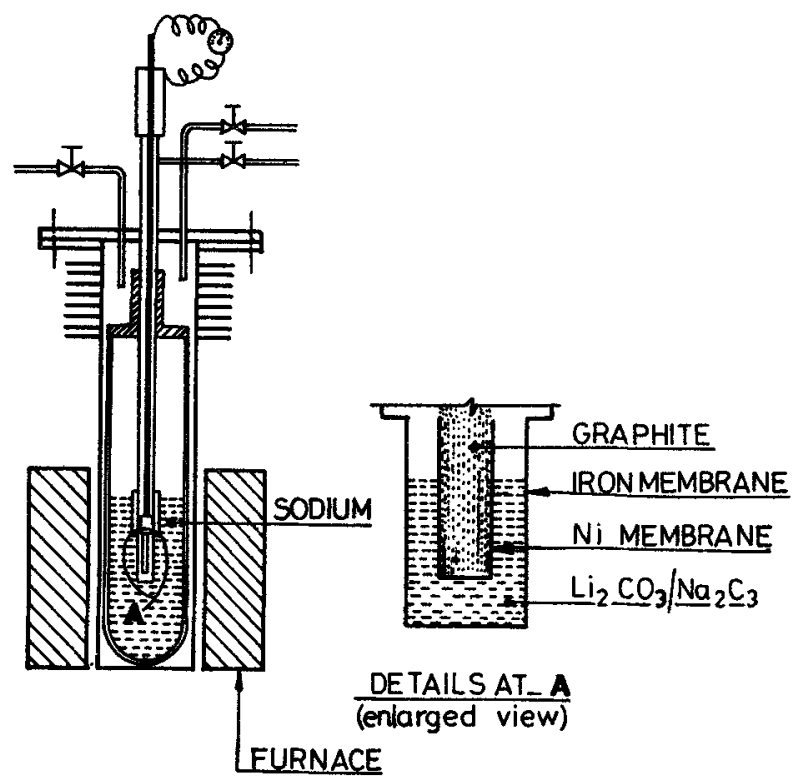

Figure 2. Carbon sensor is schematically shown here as dipping into liquid sodium contained in a test chamber.

As electrochemical sensors are much simpler to operate, efforts were made to develop such a device. Here again, the principle is that of an electrode concentration cell which can be represented as

Reference electrode/electrolyte/sample electrode.

If $a_{\mathrm{c}}^{\mathrm{R}}$ and $a_{\mathrm{c}}^{\mathrm{Na}}$ represent the carbon activities of the reference and sodium (sample) electrodes respectively, then the EMF developed is given by

$$
E=(R T / n F) \ln \left(a_{\mathrm{c}}^{\mathrm{R}} / a_{\mathrm{c}}^{\mathrm{Na}}\right) .
$$

The electrolyte is a molten mixture of sodium and lithium carbonates and the reference electrode is a nickel tube packed with graphite.

The details of the experimental assembly used in these studies are shown in figure 2. The electrolyte is contained in an Armco iron cup machined from a defect-free rod. The iron cup is welded to a $12 \mathrm{~mm}$ diameter stainless steel tube. The reference electrode is positioned at the centre of the electrolyte and the two electrodes are coupled through a Conax fitting. The EMF was measured by a high impedance millivolt meter connecting the two electrodes.

Several such sensors have been built and tested in liquid sodium in static pots. The sodium used for this purpose was prepared by distillation to avoid undissolved carbon. The sensor was found to give Nernstian response. It was also tested by measuring the carbon activity of sodium which was simultaneously equilibrated with nickel foils. By retrieving the nickel foil and determining its carbon content, one can correlate its carbon concentration with its carbon activity which should be the same as that of the sodium. This agreed very well with the carbon activity measured by the sensor in its temperature range of operation ( 820 to $960 \mathrm{~K}$ ) (Pillai and Mathews 1986). 


\section{Oxygen in sodium}

Since oxygen present in sodium enhances corrosion and activity transport in the sodium circuits of the reactors, it is important to control its level by on-line purification and continuous monitoring. Electrochemical sensors have been developed for this purpose based on the oxide-ion conducting solid electrolyte, yttria-doped thoria (YDT) (Kolodney et al 1965). In/ $\mathrm{In}_{2} \mathrm{O}_{3}$ is the preferred reference electrode while sodium containing dissolved oxygen forms the sample electrode. Thus the cell can be represented as

$$
[O]_{\mathrm{Na}} / \mathrm{YDT} / \mathrm{In}, \quad \mathrm{In}_{2} \mathrm{O}_{3} \text {. }
$$

The cell output is dependent on the oxygen concentration in sodium according to the following equation:

$$
E(\mathrm{mV})=A+B T+C T \log \left[C_{\mathrm{Na}} / C_{\mathrm{Na}}^{\mathrm{o}}\right] \text {, }
$$

where $A, B$ and $C$ are constants, $C_{\mathrm{Na}}$ the concentration of oxygen in sodium, and the superscript $o$ refers to saturation solubility at temperature $T$. The sensor assembly is shown in figure 3. The electrolyte is in the form of a high density tube. This is fitted to the sensor assembly by using viton $O$-rings. The cooling fins ensure that sodium remains frozen in this section and that the O-ring is at a low enough temperature. The 'Conoseal' joint makes a leak-tight connection to the sodium system such that the probe dips into sodium. The reference electrode is taken inside the YDT tube.

The choice of YDT as the electrolyte is based on its low LEDB (lower electrolyte domain boundary) which ensures that YDT remains an ionic conductor even at the very low oxygen potentials encountered in nuclear grade sodium. However, these



Figure 3. A YDT based oxygen sensor inserted into liquid sodium. 
probes suffer from problems such as: (i) sodium attack on the electrolyte at high oxygen levels, (ii) high cost arising from difficulties in manufacture, and (iii) unpredictable life ranging from a few hours to a few thousand hours.

In order to overcome the problems associated with YDT, particularly its non-availability, we reinvestigated the other commonly used oxide-ion conducting solid electrolyte, viz. zirconia, for use in these sensors. Calcia-stabilized zirconia (CSZ) was tried earlier by Kolodney et al (1965) but was given up owing to its electronic conductivity and susceptibility for sodium attack at the operating temperatures $(673 \mathrm{~K})$ and at low oxygen levels in sodium. When the electrolytic domain boundary of CSZ was remeasured in our laboratory, it was found that at low temperatures CSZ had better LEDB properties adequate for use with sodium. Moreover, the attack by sodium is expected to be less at low temperatures. Since the cell resistance would be high at low temperatures, a new low impedance reference electrode was designed and the cell thus developed can be represented as

$$
\mathrm{Na},[\mathrm{O}] \text { dissolved/CSZ/K, } \mathrm{K}_{2} \mathrm{O} \text {. }
$$

The operating temperature of this sensor was optimized to get acceptable cell resistance and minimum sodium attack. When this cell was tested in a sodium loop, the output was found to have a theoretical slope in the plot of EMF vs oxygen concentration, indicating a good performance of the electrolyte. The life-times achieved were about 3 to 6 months. However, these sensors showed an asymmetric potential arising out of the possible albeit slow reaction between sodium and zirconia. Since this varies from cell to cell, the meters require independent calibration. In order to overcome this problem, a strategy of stabilizing the electrolyte surface against sodium attack was resorted to, by reacting the surface with calcia and converting it into calcium zirconate, which is stabler than the product of sodium attack, viz. sodium zirconate. Since calcium zirconate is a line compound with good anionic mobility arising out of its perovskite structure it will not hinder potential development. Sensors constructed using this coated electrolyte, when tested, gave much better performance in terms of EMF scatter and electrolyte life-time. Efforts are under way to develop a stable, adherent coating that will enhance the life of the meter.

\section{Compatibility of sodium with structural materials}

The structural materials with which liquid sodium comes into contact in a fast breeder reactor include stainless and ferritic steels. Even though these materials are known to be compatible with sodium in the pure form it is important to detect even low levels of corrosion and understand the effect of impurities such as oxygen and carbon in sodium, as the anticipated life of the reactor is over 30 years.

\subsection{Corrosion in low-oxygen sodium}

In pure sodium containing low levels of oxygen (a few ppm or less), the corrosion rate is low. The mechanism of corrosion in this regime is the selective leaching of alloying elements (Thorley 1984). Substitutional alloying elements such as $\mathrm{Cr}, \mathrm{Ni}$ and $\mathrm{Mn}$ are leached out in the hot legs and this process is known to be temperature dependent. The loss of alloying elements makes the depleted layer of the material ferritic (Borgstedt 1977). 
This process of dissolution is dependent on the solubility of the metallic element in sodium. The temperature dependence of the solubility of an element in liquid sodium can be expressed as

$$
\log S=A-B / T,
$$

where $S$ is solubility, $T$ the temperature in Kelvin, and $A$ and $B$ are constants. When solubility is small $S$ is expressed as wppm. The solubility of $\mathrm{Mn}$ and Mo in luquid sodium was measured in our laboratory using an equilibration technique (Periaswami et al 1982). Since the solubility is dependent on the oxygen concentration of sodium, the measurements were carried out in oxygen-gettered sodium. The solubility expressions thus obtained are given below along with the temperature range of their applicability:

$$
\begin{aligned}
& \log S(\text { wppm Mn })=3 \cdot 6406-\frac{2601 \cdot 7}{T} \quad(T=550-811 \mathrm{~K}), \\
& \log S(\text { wppm Mo })=2 \cdot 738-\frac{2200}{T} \quad(T=500-720 \mathrm{~K}) .
\end{aligned}
$$

Figure 4 gives the solubilities of the alloying elements in sodium as a function of temperature. It is clear why nickel and manganese are preferentially leached out from the steel under low oxygen conditions. The activity of molybdenum in the austenitic phase being low, it does not get leached out readily. The loss of alloying elements makes the $\gamma$-phase unstable and hence a ferritic layer is formed. It has been observed that after $\sim 2000 \mathrm{~h}$ of operation at $755^{\circ} \mathrm{C}$ in sodium containing $4 \mathrm{ppm}$ dissolved oxygen, the depleted zone at the austenitic steel surface becomes $25 \mu \mathrm{m}$ deep and the ferritic layer becomes $15 \mu \mathrm{m}$ thick (Weeks and Isacs 1973). In fast flowing sodium the kinetics of selective leaching process gets controlled by the diffusion of alloying elements in the steel matrix.

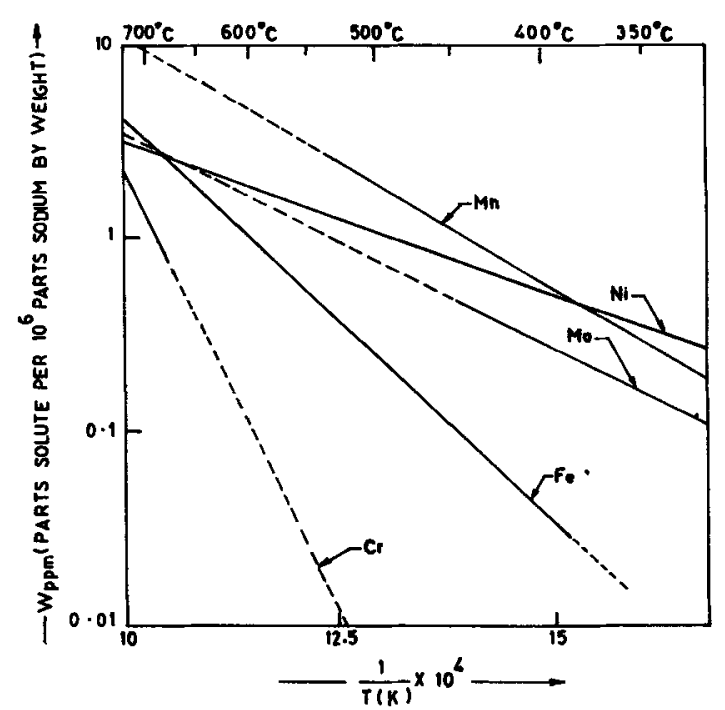

Figure 4. Solubilities of the alloying elements of stainless steel in liquid sodium. 


\subsection{Effect of dissolved oxygen}

The corrosion rate of stainless steel is dependent on the oxygen concentration in sodium. Thorley and Tyzack (1973) deduced the following equation describing the corrosion of stainless steel in fast flowing sodium:

$$
\log _{10} S=2 \cdot 44+1 \cdot 5 \log _{10}[\mathrm{O}]-\frac{18,000}{2 \cdot 3 R T}
$$

where $S$ is the loss of material expressed in mil/y, [O] the oxygen concentration in wppm, $R$ the gas constant, and $T$ the absolute temperature. This strong dependence of corrosion rate on oxygen concentration indicates a chemical reaction involving oxygen.

One can envisage three possible situations based on the stability of the oxide of the alloying elements. If the oxide is less stable than sodium oxide, then it is reduced to the metal by sodium. If the oxide is much stabler than $\mathrm{Na}_{2} \mathrm{O}$, then the metal is readily oxidized by sodium. In the intermediate case of comparable stability, ternary oxides of sodium and the alloying element are likely to be formed. The alloying elements $\mathrm{Fe}, \mathrm{Cr}, \mathrm{Ni}, \mathrm{Mn}$ and $\mathrm{Mo}$ generally fall in the third category. Among these the oxides of $\mathrm{Fe}, \mathrm{Ni}$ and $\mathrm{Mo}$ are less stable and hence form ternary oxides of lower stability than those of $\mathrm{Cr}$ and $\mathrm{Mn}$.

\subsection{Na-Cr-O system}

As the oxygen level in sodium is increased, the first ternary compound that is formed on stainless steel is $\mathrm{NaCrO}_{2}$. Hence it is of interest to find the threshold oxygen level above which this compound would form, thus enhancing the corrosion of steel. This can be directly obtained by measuring the equilibrium oxygen potential in the phase field $\mathrm{Na}-[\mathrm{Cr}]_{\mathrm{ss}}-\mathrm{NaCrO}_{2}$. It can also be deduced from the free energy of formation of $\mathrm{NaCrO}_{2}$. These two sets of values obtained from literature were found to be quite different. In view of this both were remeasured in our laboratory.

Direct measurement of the oxygen potential in sodium in equilibrium with chromium metal and $\mathrm{NaCrO}_{2}$ was carried out using an oxygen probe. From the measured EMF at different temperatures in the range 657 to $825 \mathrm{~K}$ the equilibrium oxygen potential of the $\mathrm{Na}-\mathrm{Cr}-\mathrm{NaCrO}_{2}$ system was deduced as

$$
\Delta \bar{G}_{\mathrm{O}_{2}}=800847+147.85 T \mathrm{~J} / \mathrm{mol} \mathrm{O}{ }_{2} \quad( \pm 1.35 \mathrm{~kJ}) \text {. }
$$

This was used to deduce the threshold oxygen level for $\mathrm{NaCrO}_{2}$ formation in sodium $-18 / 8$ steel system. The values were $17 \cdot 37 \mathrm{wppm}$ at $773 \mathrm{~K}$ and $27 \cdot 78 \mathrm{wppm}$ at $873 \mathrm{~K}$.

The free energy of formation of $\mathrm{NaCrO}_{2}$ was remeasured using $\mathrm{Knudsen}$ cell mass spectrometry (Gnanasekaran and Mathews 1986). The vapour pressure of sodium over the phase field $\mathrm{Cr}(\mathrm{s})-\mathrm{Cr}_{2} \mathrm{O}_{3}-\mathrm{NaCrO}_{2}(\mathrm{~s})$ was measured accurately and using this and the reaction

$$
\mathrm{Cr}(\mathrm{s})+\mathrm{NaCrO}_{2}(\mathrm{~s})=2 \mathrm{Cr}_{2} \mathrm{O}_{3}(\mathrm{~s})+3 \mathrm{Na}(\mathrm{g}),
$$

the free energy of formation of $\mathrm{NaCrO}_{2}$ was derived as

$$
\Delta G_{f, T}^{\mathrm{o}}\left(\mathrm{NaCrO}_{2}\right)=-870773+193 \cdot 171 T \mathrm{~J} / \mathrm{mol}( \pm 1 \cdot 3 \mathrm{~kJ}) \text {. }
$$


Considering the equilibrium

$$
\mathrm{Na}(1)+[\mathrm{Cr}]_{\mathrm{ss}}+\mathrm{O}_{2}(g)=\mathrm{NaCrO}_{2}(\mathrm{~s})
$$

relevant to the sodium-steel system and using the measured free energy of formation of $\mathrm{NaCrO}_{2}$, the oxygen potential in this system and hence the threshold oxygen level were calculated. The values were $0.66 \mathrm{wppm}$ at $773 \mathrm{~K}$ and $1.93 \mathrm{wppm}$ at $873 \mathrm{~K}$.

This discrepancy between the two sets of values can be understood by considering the quaternary system $\mathrm{Na}-\mathrm{Cr}-\mathrm{O}-\mathrm{C}$ (Gnanasekaran and Mathews 1986). Carbon is an unavoidable impurity in sodium. Carbides of chromium are very stable and it is probable that an impervious layer of carbides is formed on the stainless steel surface. Taking reactions such as

$$
\mathrm{Cr}_{23} \mathrm{C}_{6}(\mathrm{~s})+23 \mathrm{Na}(1)+23 \mathrm{O}_{2}(\mathrm{~g})=23 \mathrm{NaCrO}_{2}+6[\mathrm{C}]_{\mathrm{Na}}
$$

into consideration, a phase stability diagram of the $\mathrm{Na}-\mathrm{Cr}-\mathrm{O}-\mathrm{C}$ system was constructed as given in figure 5 . This diagram explains the following observations in sodium loops reported in the literature: (i) only chromium carbide deposits are noticed in sodium loops when oxygen level is low (Kolster 1975), and (ii) threshold oxygen levels for $\mathrm{NaCrO}_{2}$ formation directly measured in sodium are higher than those computed by considering only the $\mathrm{Na}-\mathrm{Cr}-\mathrm{O}$ system.

\section{$7.4 \mathrm{Na}-\mathrm{Mo}-\mathrm{O}$ system}

The ternary system involving molybdenum was investigated recently in our laboratory (Gnanasekaran et al 1989). Through in-sodium measurements and isopiestic

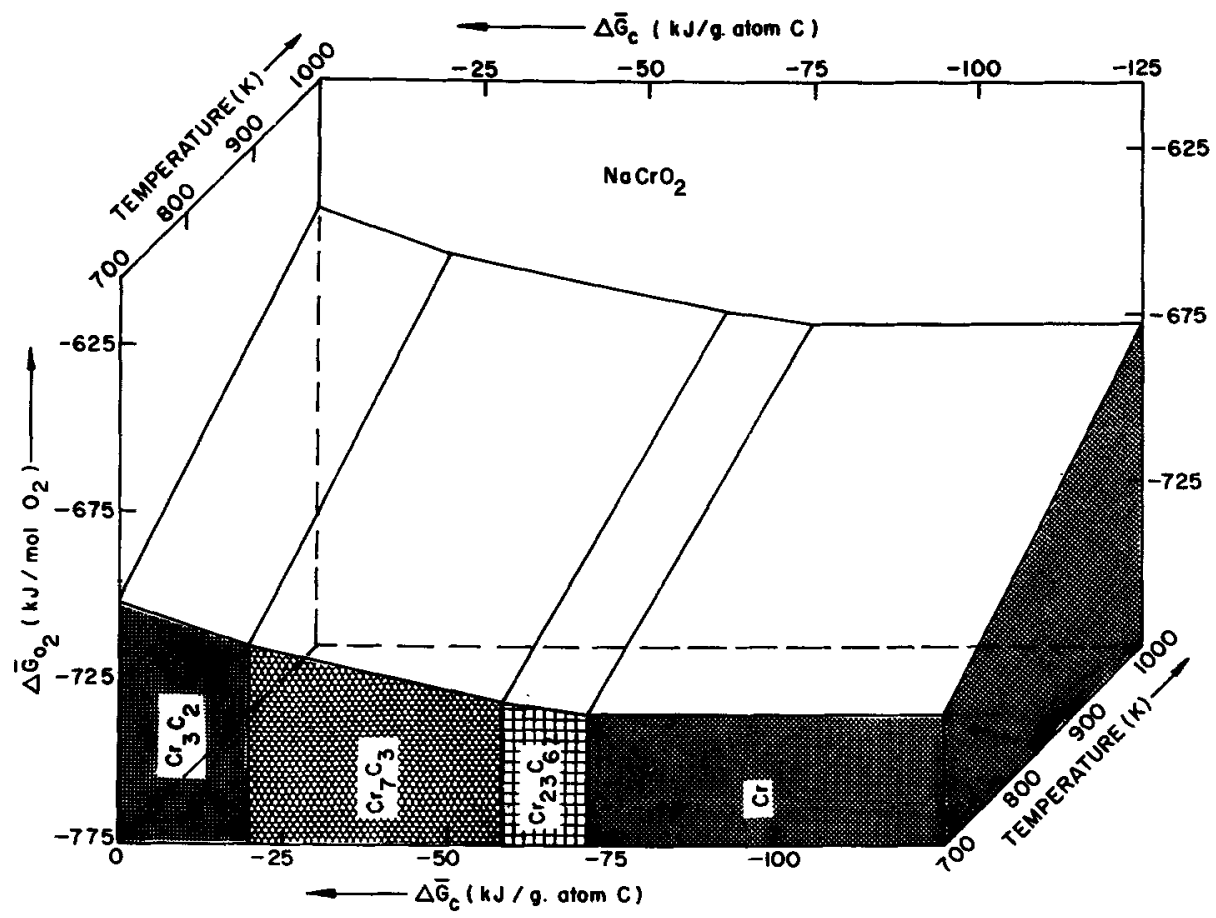

Figure 5. A section of the $\mathrm{Na}-\mathrm{Cr}-\mathrm{O}-\mathrm{C}$ phase diagram. Since chemical potentials are plotted, biphasic regions are represented by lines and monophasic regions by areas. 
equilibrations, the phases that coexist with sodium and molybdenum were identified and characterized. It was found that up to $681 \mathrm{~K}$ only $\mathrm{Na}_{2} \mathrm{O}$ exists in equilibrium with the metallic phases. Above this temperature $\mathrm{Na}_{4} \mathrm{MoO}_{5}$ is the equilibrium phase. The equilibrium oxygen potential in the $\mathrm{Na}-\mathrm{Mo}-\mathrm{Na}_{4} \mathrm{MoO}_{5}$ phase field was also measured to yield the following expression:

$$
\Delta \bar{G}_{\mathrm{O}_{2}}=-762889+174 \cdot 452 T( \pm 2 \cdot 1 \mathrm{~kJ}) \text {. }
$$

This corresponds to a threshold oxygen concentration of $843 \mathrm{ppm}$ at $700 \mathrm{~K}$ and $974 \mathrm{ppm}$ at $800 \mathrm{~K}$ for the formation of $\mathrm{Na}_{4} \mathrm{MoO}_{5}$. These data adequately explain the corrosion behaviour with respect to molybdenum in stainless steels. At low temperatures $(681 \mathrm{~K})$ only metallic dissolution process is possible. However, considering the solubility of Mo in sodium and its activity in stainless steel, measurable leaching may not take place. At high temperatures $(681 \mathrm{~K})$ the ternary oxide gets formed only at high oxygen concentrations which are not encountered in reactor loops.

\section{$7.5 \mathrm{Na}-\mathrm{Fe}-\mathrm{O}$ system}

Bulk corrosion of structural steels in sodium systems is essentially the loss of iron through oxidation. However, the thermodynamic data available in the literature suggest that a ternary oxide is likely to be formed only at high oxygen levels $(\sim 1000 \mathrm{ppm})$. This is contrary to the experience on corrosion in sodium systems. Therefore, this system was investigated in detail through experiments involving equilibration of iron oxides with liquid sodium, pseudo-isopiestic equilibration of binary and ternary oxides with sodium vapour, and solid state reactions of oxides of iron and sodium. In this way, it was possible to establish the phase equilibria in this ternary system. Differential thermal analysis and oxygen potential measurements

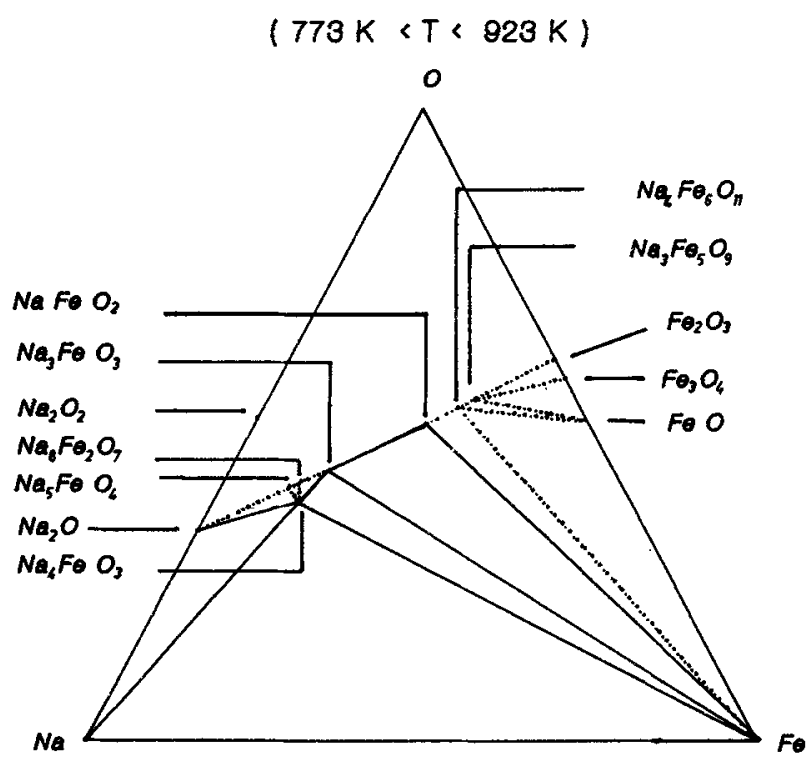

Figure 6. A section of the $\mathrm{Na}-\mathrm{Fe}-\mathrm{O}$ phase diagram as established in our laboratory. Phase equilibria represented by dotted lines are to be confirmed. 
were carried out as a function of temperature in the ternary phase field involving sodium.

As a result of these studies, the partial phase diagram shown in figure 6 was established in the temperature range $773 \mathrm{~K}$ to $923 \mathrm{~K}$ (Sridharan et al 1993). Up to a temperature of $626 \mathrm{~K}$ it was found that liquid sodium coexists with $\mathrm{Fe}$ (solid) and $\mathrm{Na}_{2} \mathrm{O}$ (solid). At intermediate temperatures $(626 \mathrm{~K}<T<760 \mathrm{~K})$, no ternary oxide appears to be stable in sodium. However, oxygen potential data suggest some kind of association between iron and oxygen. DTA results are also consistent with this picture. This may explain the enhanced corrosion of iron in liquid sodium.

\section{Sodium loop}

The irradiation of stainless steel components in fast reactors leads to the formation of radionuclides such as ${ }^{54} \mathrm{Mn},{ }^{60} \mathrm{Co}$ and ${ }^{59} \mathrm{Fe}$, which get released into the sodium coolant circuit as a result of the corrosion of steel by sodium. In addition to this, the failure of fuel pin cladding leads to the release of the fission products $\left({ }^{137} \mathrm{Cs}\right.$, ${ }^{134} \mathrm{Cs}$, ${ }^{131} \mathrm{I}$, etc) with fairly high gamma energies and long half-lives. These radionuclides get deposited on various parts of the primary coolant systems. This results in high radiation fields at these locations causing problems during operation and maintenance. To minimize such problems, it is essential to develop suitable radionuclide traps (RNT) to concentrate and confine the radioisotopes of interest in appropriate locations of the coolant systems. To predict the release, transport and deposition behaviour of radionuclides of interest in reactor circuits, suitable models have to be developed describing the activity transport in fast reactor coolant circuits, based on data obtained from clean loop experiments.

A radioactive sodium chemistry loop (RSCL) has been fabricated and commissioned in our laboratory to carry out studies on activity transport. This loop will also serve as a facility to test the long-term performance of on-line meters for impurities in sodium and to study the fuel-coolant chemical interaction occurring on account of fuel pin failure.

The RSCL consists of a main loop to carry out activity transport studies and an auxiliary loop to characterize the sodium. Reactor core conditions with respect to sodium flow, temperature and purity can be simulated in this loop. Thus, release behaviour of activated corrosion products and fuel-coolant chemical interactions can be studied. The auxiliary loop consists of various monitors for impurities in sodium, as well as provision to incorporate RNT for ${ }^{137} \mathrm{Cs}$. The operations of the loop such as control of temperatures at various locations and data logging are computer-controlled. A number of safety systems such as sodium leak detectors, smoke and fire detectors, etc. are incorporated. It is hoped that activity transport studies in this sodium loop will lead to a model that predicts the behaviour of radioactive isotopes in the reactor circuits and to radionuclide traps that would mitigate the problem of activity build-up in areas that need human intervention.

\section{References}

Asher R C, Kirstein T B and Talchard A C 1977 Report AERE-8020, Harwell, UK

Borgstedt H U 1977 Rev. Coating Corros. 2121 
Borgstedt H U and Mathews C K 1987 Applied chemistry of alkali metals (New York: Plenum Press) Funada T, Nihei I, Yuhara S and Nakasuji T 1979 Nucl. Technol. 45158

Gnanasekaran T and Mathews C K 1986 J. Nucl. Mater. 140202

Gnanasekaran T, Mahendran K H, Kutty K V G and Mathews C K 1989 J. Nucl. Mater. 165210

Gnanasekaran T, Mahendran K H, Sridharan R, Ganesan V, Periaswami G and Mathews C K 1990 Nucl. Technol. 90408

Kolodney M, Minushkin B G and Steinmetz H 1965 Electrochem. Technol. 3244

Kolster B W 1975 J. Nucl. Mater. 55155

Mathews C K 1982 Pure Appl. Chem. 54807

Periaswami G, Ganesan V, Rajan Babu S and Mathews C K 1982 Material behaviour and physical chemistry in liquid metal systems (ed.) H U Borgstedt (New York: Plenum Press) p. 411

Pillai S R and Mathews C K 1986 J. Nucl. Technol. 90408

Smith C A 1974 Proc. int. conf. on liquid alkali metals, Nottingham, UK (London: Br. Nucl. Energy Soc.)

Sridharan R, Gnanasekaran T and Mathews C K 1993 J. Alloys Compounds 1919

Thorley A W and Tyzack C 1973 Liquid alkali metals (London: BNES) p. 257

Thorley A W 1984 Liquid metal engineering and technology (London: BNES) Vol. 3, p. 31

Weeks J R and Isacs H S 1973 in Advances in corrosion science and technology (eds) M G Fontana and R W Stachle (New York: Plenum Press) Vol. 3, p. 1 